\title{
Lipopolysaccharide signaling in endothelial cells
}

\author{
Shauna M Dauphinee ${ }^{1,2}$ and Aly Karsan ${ }^{1,2,3,4}$ \\ ${ }^{1}$ Department of Medical Biophysics, British Columbia Cancer Agency, Vancouver, British Columbia, Canada; \\ ${ }^{2}$ Experimental Medicine Program, University of British Columbia, Vancouver, British Columbia, Canada; \\ ${ }^{3}$ Department of Pathology and Laboratory Medicine, British Columbia Cancer Agency, Vancouver, British \\ Columbia, Canada and ${ }^{4}$ Department of Pathology and Laboratory Medicine, University of British Columbia, \\ Vancouver, British Columbia, Canada
}

\begin{abstract}
Sepsis is the systemic immune response to severe bacterial infection. The innate immune recognition of bacterial and viral products is mediated by a family of transmembrane receptors known as Toll-like receptors (TLRs). In endothelial cells, exposure to lipopolysaccharide (LPS), a major cell wall constituent of Gramnegative bacteria, results in endothelial activation through a receptor complex consisting of TLR4, CD14 and MD2. Recruitment of the adaptor protein myeloid differentiation factor (MyD88) initiates an MyD88-dependent pathway that culminates in the early activation of nuclear factor- $\kappa B(N F-\kappa B)$ and the mitogen-activated protein kinases. In parallel, a MyD88-independent pathway results in a late-phase activation of NF- $\kappa \mathrm{B}$. The outcome is the production of various proinflammatory mediators and ultimately cellular injury, leading to the various vascular sequelae of sepsis. This review will focus on the signaling pathways initiated by LPS binding to the TLR4 receptor in endothelial cells and the coordinated regulation of this pathway.
\end{abstract}

Laboratory Investigation (2006) 86, 9-22. doi:10.1038/labinvest.3700366; published online 7 November 2005

Keywords: lipopolysaccharide; Toll-like receptors; innate immunity; endothelial cell; inflammation

Sepsis is the leading cause of mortality in critically ill patients. ${ }^{1}$ The development of sepsis occurs as a result of a systemic inflammatory response to a severe bacterial infection. ${ }^{2}$ Under normal conditions, a controlled cellular response to bacterial products protects the host from infection. In sepsis, hyperactivation of the immune response leads to the excessive production of various proinflammatory cytokines and cellular injury. ${ }^{2}$ In mammals, the innate immune system is the first line of host defense involved in detecting the wide variety of invading microbial pathogens. ${ }^{3}$ Receptors of the innate immune system are activated by microbial components such as lipopolysaccharide (LPS) (also known as endotoxin), which is a key molecule involved in the initiation of the sepsis syndrome. ${ }^{3}$

Correspondence: Dr A Karsan, MD, Department of Medical Biophysics, British Columbia Cancer Research Centre, 675 West 10th Avenue, Vancouver, British Columbia, Canada V5Z 1L3.

E-mail: akarsan@bccrc.ca

Funding: CIHR Grant \# MOP-64409

Received 1 September 2005; accepted 2 October 2005; published online 7 November 2005

\section{Endothelial dysfunction in sepsis}

The endothelium plays a major role in the pathogenesis of sepsis. Endothelial cells line the inner wall of blood vessels, lying at the interface between circulating blood and the surrounding tissue. ${ }^{4}$ Although these cells are potentially highly susceptible to injury given that they are the first cells exposed to invading pathogens circulating in the bloodstream, endothelial cells have a remarkable capacity to protect themselves. ${ }^{4}$ The endothelium serves a multitude of functions that help to maintain organ homeostasis, including vasoregulation, selective vascular permeability and providing an anticoagulant surface. ${ }^{5}$ However, during infection, the normal physiological functions of the endothelium are perturbed, contributing to the organ failure characteristic of sepsis. ${ }^{6}$ Although there is debate on the extent of vascular dysfunction that is due to the direct effects of LPS on the endothelium, relative to the effects that are secondary to the release of inflammatory mediators, such as tumor necrosis factor $\alpha(\mathrm{TNF} \alpha)$, interleukin-1 $\beta$ (IL-1 $\beta$ ), interferons (IFNs) and others, from macrophages and immune cells, ${ }^{7}$ this review will concentrate on the direct cellular and molecular effects of LPS on the endothelium. 


\section{Vasoregulation}

The endothelium secretes a diversity of paracrine agents that mediate vascular tone. ${ }^{8}$ Vasodilating compounds such as nitric oxide (NO) and prostacyclin increase the diameter of the intravascular space by relaxing adjacent smooth muscle cells within the vessel wall. ${ }^{9}$ These mediators counteract vasoconstrictors such as angiotensin to maintain a balance in vascular resistance. ${ }^{10}$ Upon exposure to LPS, endothelial cells upregulate the expression of inducible NO synthase (NOS2), which leads to an increase in the production of NO. ${ }^{11}$ The use of pharmacological NOS inhibitors in patients with septic shock increases blood pressure and restores vascular resistance. ${ }^{12}$ Furthermore, NOS2-deficient mice do not experience the impaired vasoconstriction associated with endotoxemia. ${ }^{13}$ This excessive production of vasoactive mediators, such as NO, results in the impaired vasoconstriction and associated hypotension seen in patients with sepsis. ${ }^{14}$

\section{Vascular Permeability}

Endothelial cells serve as a selective barrier for the exchange of fluid and macromolecules from the vascular compartment to the tissue..$^{5}$ An increase in vascular permeability is mediated by retraction of the endothelium and phosphorylation of the light chain of nonmuscle myosin. ${ }^{15}$ This phosphorylation event induces a conformational change in the myosin light chain that promotes the interaction of actin and myosin, thereby supporting the contractile state. $^{15}$ A recombinant form of LPS derived from the horseshoe crab, Limulus polyphemus, that is designed to neutralize endotoxin action, has been shown to prevent LPS-induced actin depolymerization, thereby preventing an LPS-induced increase in endothelial permeability. ${ }^{16}$ LPS also directly contributes to endothelial barrier dysfunction through a caspase-mediated cleavage of junctional proteins involved in regulating transport of material between the vascular space and tissue. ${ }^{17}$

\section{Leukocyte Recruitment and Adhesion}

During the healing process, circulating leukocytes are recruited to the endothelium, where they adhere and traverse between the endothelial cells to enter the site of inflammation. ${ }^{18}$ The initial step in this process involves recruitment of the leukocyte to the endothelial surface through the association between selectin molecules, which are found on the surface of both the circulating leukocytes (L-selectin) and the endothelium (E- and P-selectin), and sialylated, carbohydrate moieties on the contacting cell. ${ }^{18}$ The initial selectin-mediated rolling followed by tighter adhesion to the endothelium is also mediated by the integrin family. Integrins are heterodimeric molecules expressed on the surface of leukocytes that facilitate a strong association with cell-adhesion molecules (CAMs) on the surface of cytokinestimulated endothelial cells (ICAM-1, VCAM-1). ${ }^{19}$ LPS directly increases expression of E-selectin and integrin counter receptors, ${ }^{20}$ and the upregulation of this adhesion molecule expression requires the nuclear localization of nuclear factor-kappa B (NF$\kappa \mathrm{B}){ }^{21,22}$ In septic patients, elevated levels of endothelial selectins correlate with poor prognosis. ${ }^{23}$ Furthermore, mice deficient for endothelial selectins show increased survival in an animal model of sepsis. $^{24}$

\section{Hemostasis}

Under normal physiological conditions, the endothelium is maintained in an anticoagulatory state by the action of thrombin on the surface of the endothelial cell. ${ }^{25}$ Thrombin, bound to thrombomodulin, cleaves protein $\mathrm{C}$ into its active form, activated protein $\mathrm{C}$, which inhibits the activated coagulation factors, Va and VIIIa. ${ }^{26}$ During sepsis, the endothelium shifts from an anticoagulant surface to a procoagulant surface by reduced expression of anticoagulatory molecules such as thrombomodulin, thereby shifting the action of thrombin towards the cleavage of fibrinogen and the generation of fibrin clots. ${ }^{27,28}$ Furthermore, LPS may directly induce the prothrombotic state by upregulating the endothelial expression of tissue factor through an NF- $\kappa \mathrm{B}$-dependent mechanism. ${ }^{29}$ These changes contribute to the disseminated intravascular coagulation characteristic of sepsis.

\section{Toll-like receptor (TLR)4 signaling}

LPS is a key component of the cell wall of Gramnegative bacteria. ${ }^{30}$ It is composed of three structural elements: a core oligosaccharide, an O-specific chain made up of repeating sequences of polysaccharides and a lipid A component, which is responsible for the proinflammatory properties of LPS. $^{30}$ The binding of LPS to the surface of endothelial cells results in endothelial activation, as demonstrated by the expression of proinflammatory cytokines and adhesion molecules, and, in some cases, endothelial apoptosis. ${ }^{31}$ LPS also activates monocytes and macrophages to stimulate the production of proinflammatory mediators, which in turn modulate endothelial function. Collectively, this initiates a parallel cascade of events that contribute to the clinical manifestations of sepsis.

The TLRs are a family of pattern recognition receptors that are classified on the basis of homology of the cytoplasmic domain with that of the interleukin-1 receptor (IL-1R) family, which is known as the Toll/IL-1R (TIR) domain. ${ }^{32}$ To date, there have been 12 TLRs identified in mice ${ }^{33}$ and 10 TLRs in humans. ${ }^{34-36}$ TLR4 was established as the LPS signaling receptor based on genetic evidence from 
the LPS-insensitive mouse strain, C3H/HeJ, which has a single point mutation in the TIR domain of TLR4. In addition, the C57BL/10ScCr strain of mice has a null mutation in the TLR4 gene that also confers resistance to LPS. ${ }^{37}$ However, it should be noted that LPS from some bacterial species, such as Porphyromonas gingivalis, activate cells through TLR2. ${ }^{38}$

The first host protein involved in the recognition of LPS is LPS-binding protein (LBP). ${ }^{39}$ LBP is an acute-phase protein, the role of which is to bring LPS to the cell surface by binding to LPS and forming a ternary complex with the LPS receptor molecule, CD14. ${ }^{39}$ In endothelial cells, LBP also serves to enhance LPS uptake. ${ }^{40}$ Formation of the complex between LPS and CD14 facilitates the transfer of LPS to the LPS receptor complex composed of TLR4 and MD2. ${ }^{41}$ CD14 is found in two forms: a membrane-bound glycosylphosphatidylinositol (GPI)-anchored protein (mCD14) and as a soluble proteolytic fragment lacking the GPI anchor (sCD14). ${ }^{42}$ Endothelial cells lack mCD14 found on many cell types, such as macrophages and monocytes, and thus require sCD14 cleaved off cells bearing mCD14 and found circulating in the plasma. ${ }^{43}$ In addition to the production of sCD14 by proteolysis of the membrane-bound receptor, monocytic cell lines also secrete sCD14 molecules that never acquire a GPI anchor. ${ }^{44}$ Although it is widely accepted that endothelial cells do not express mCD14, early-passage human umbilical vein endothelial cells (HUVECs) have been reported to synthesize and express mCD14 at levels that are capable of supporting LPS-induced cell activation. ${ }^{45}$ However, LPS activation of endothelial cells is primarily achieved using sCD $14 .{ }^{46}$ Nevertheless, in vivo expression of mCD14 on endothelial cells has not been examined. Since CD14 lacks a transmembrane domain, it does not have the capability to initiate intracellular signaling events. ${ }^{42}$ Concerted efforts over several years have led to the discovery of the TLR4/MD2 receptor complex as the signaling entity for LPS. MD2 is a secreted glycoprotein that functions as an indispensable extracellular adaptor molecule for LPS-initiated signaling events, ${ }^{47}$ perhaps by aiding in ligand recognition. ${ }^{48}$

In addition to CD14, TLR4 and MD2, Triantifilou et $a l^{49,50}$ have proposed that other molecules may be involved in CD14-independent signal initiation in macrophages. Studies using affinity chromatography, and later confirmed by fluorescence resonance energy transfer (FRET), revealed that LPS associates with the heat shock proteins, Hsp70 and Hsp90, chemokine receptor 4 (CXCR4) and growth differentiation factor 5 (GDF5). ${ }^{49,50}$

In human coronary artery endothelial cells, TLR4 functions intracellularly, ${ }^{51}$ suggesting that LPS uptake may be necessary for optimal signal transduction. Similarly, TLR4 colocalizes with LPS within the Golgi of intestinal epithelial cells ${ }^{52}$ and functions within this intracellular compartment to recognize internalized LPS. ${ }^{53}$ Indeed, TLR4 is the primary receptor for transduction of the LPS signal, but it is not responsible for the internalization of LPS, pointing to the existence of another receptor for the uptake of LPS. ${ }^{40}$ LPS internalization in endothelial cells via scavenger receptor-dependent pathways is suggested to be important in the clearance of LPS. $^{54}$ However, overexpression of a fluorescent TLR4 in human embryonic kidney (HEK293) cells showed that TLR4 cycled between the plasma membrane and the Golgi complex, but the initiation of LPS signaling occurred at the membrane, as evidenced by an inability to disrupt signaling using brefeldin A, a pharmacological agent that disrupts the Golgi. ${ }^{55}$ Thus, further studies are required to definitively elucidate the subcellular location in which LPS activates endothelial cells. In contrast, in mononcytes that express mCD14, TLR4 is found exclusively on the cell surface localized within discrete lipid microdomains following LPS stimulation. ${ }^{56}$

The TLR4 signaling cascade initiated following LPS binding is enhanced by homodimerization of the receptor and subsequent recruitment of TIRdomain-containing adaptor molecules (TIRAP) to the cytoplasmic domain of the receptor. ${ }^{57,58}$ These adaptors include myeloid differentiation factor 88 (MyD88), MyD88 adaptor-like protein (Mal), also called TIRAP, TIR-containing adaptor inducing IFN $\beta$ (TRIF), also known as TIRAP-1 (TICAM-1), and TRIF-related adaptor molecule (TRAM), also called TIRAP-2 (TICAM-2). ${ }^{59}$

Activation of TLR4 leads to stimulation of both a MyD88-dependent and a MyD88-independent pathway. ${ }^{60}$ The major players involved in eliciting the functional effects of LPS within endothelial cells are activated through the NF- $\kappa \mathrm{B}$, mitogen-activated protein kinase (MAPK) and phosphatidylinositol 3-kinase (PI3K)/Akt pathways. These pathways regulate the balance between cell viability and inflammation.

\section{MyD88-Dependent Signaling}

\section{$N F-\kappa B$ activation}

MyD88 was originally cloned as an adaptor molecule within the IL-1R complex and shown to possess a C-terminal TIR domain and an N-terminal death domain (DD) that recruits the serine/threonine kinase, IL-1 receptor-associated kinase (IRAK). ${ }^{61}$ During MyD88-dependent signaling, MyD88 is recruited to the TLR4 receptor through interaction with the TIR domain of TLR4. ${ }^{62}$ This complex in turn facilitates the recruitment of IRAK1 and IRAK4 via a DD present in both molecules. ${ }^{61,63}$ Upon LPS stimulation, TIRAP also associates with TLR4 via a TIR-TIR interaction, and is essential for MyD88dependent signaling. ${ }^{64}$ This is apparent in TIRAPdeficient mice, which exhibit delayed kinetics with respect to NF- $\kappa \mathrm{B}$ and MAPK activation. ${ }^{65}$ In 
endothelial cells, TIRAP has been shown to mediate LPS-induced NF- $\kappa \mathrm{B}$ activation and apoptosis. ${ }^{6}$ However, the precise role of TIRAP has not been fully elucidated. The binding of IRAK4 to the receptor complex facilitates the transphosphorylation of IRAK1, inducing IRAK1 kinase activity. ${ }^{67}$ Ectopic expression of a kinase-deficient IRAK4 dramatically reduced both IRAK1 phosphorylation and downstream NF- $\kappa$ B activation. ${ }^{63}$ Furthermore, IRAK4 knockout mice have severely impaired TLR signaling, indicating that IRAK4 kinase activity is essential for LPS signaling. ${ }^{68}$ The autophosphorylation and activation of IRAK1 results in the ability to bind TNF receptor-associated factor-6 (TRAF6). ${ }^{69}$ TRAF6 contains an N-terminal domain comprised of a RING finger and several zinc fingers, which mediate downstream signaling, and a C-terminal domain involved in self-association and heterologous protein interactions. ${ }^{70}$

The complex of IRAK1 and TRAF6 dissociates from the receptor to form a complex at the membrane with transforming growth factor- $\beta$ (TGF$\beta$ )-activated kinase 1 (TAK1) and the adaptor molecules, TAK1-binding protein 1 and 2 (TAB1 and TAB2). ${ }^{71}$ TAB1 functions as an activator of TAK1, ${ }^{72}$ while TAB2 links TAK1 to TRAF6 and facilitates the ubiquitination of TRAF6. ${ }^{73,74}$ More recently, a third adaptor molecule has been identified, TAB3, which also interacts with TAK1 and mediates activation of NF- $\kappa \mathrm{B}^{75}$ Although TAK1 phosphorylation occurs at the membrane and is dependent on the formation of the TRAF6-TAK1TAB1-TAB2-TAB3 complex, it does not become active until the complex translocates to the cytoplasm. ${ }^{71}$ Here, it forms a complex with the ubiquitin conjugating enzyme Ubc13 and the Ubc-like protein, Uev1A, to catalyze the formation of a polyubiquitin chain linked through lysine 63 (K63) of ubiquitin. ${ }^{76}$ When TAK1 is activated, IRAK1 is released from the complex and eventually degraded by the ubiquitinproteasome system. ${ }^{77}$ TRAF6 is recycled through the process of deubiquitination. ${ }^{78}$ The formation of K63-linked polyubiquitin chains on TRAF6 results in TAK1-mediated phosphorylation of the I $\kappa$ B kinase (IKK) complex, composed of two catalytic subunits, IKK $\alpha$ and IKK $\beta$, and a regulatory subunit, IKK $\gamma$, also known as NF- $\kappa \mathrm{B}$ essential modulator (NEMO) ${ }^{79}$ Activation of IKK involves the TRAFinteracting protein with a forkhead-associated (FHA) domain (TIFA) protein. ${ }^{80}$ TIFA promotes the oligomerization of TRAF6 and enhances the autoubiquitinating activity of TRAF6, thereby facilitating downstream activation of NF- $\kappa \mathrm{B}$ and JNK. ${ }^{80}$ Activation of the IKKs leads to downstream phosphorylation of members of the inhibitor of NF- $\kappa \mathrm{B}$ $(\mathrm{I} \kappa \mathrm{B})$ family, resulting in ubiquitin-directed proteasome-mediated degradation of the $\mathrm{I} \kappa \mathrm{B}$ members, thus permitting the release and nuclear translocation of the transcription factor, NF- $\kappa \mathrm{B} \cdot{ }^{81}$ In endothelial cells, degradation of the $\mathrm{I} \kappa \mathrm{B}$ protein is dependent on its tyrosine phosphorylation and is specific to the $\mathrm{I} \kappa \mathrm{B} \alpha$ isoform, while $\mathrm{I} \kappa \mathrm{B} \beta$ and $\mathrm{I} \kappa \mathrm{B} \gamma$ protein levels remain unchanged following LPS stimulation. ${ }^{82}$ As will be discussed below, several other parallel pathways have an impact on TLR4mediated NF- $\kappa \mathrm{B}$ activation, including PI3K, receptor-interacting protein (RIP) and the MAPKs. In nonendothelial cells, various PKC isoforms have also been implicated in NF- $\kappa$ B activation ${ }^{83,84}$ (Figure 1).

\section{PI3K activation}

PI3Ks are a family of kinases that catalyze the phosphorylation of phosphoinositides. ${ }^{85}$ The phosphorylated lipid products, phosphatidylinositol (PtdIns) 3,4-bisphosphate and PtdIns 3,4,5-triphosphate, then act as second messengers to activate downstream events, including activation of Akt. ${ }^{86} \mathrm{~B}$ cells isolated from PI3K-deficient mice fail to

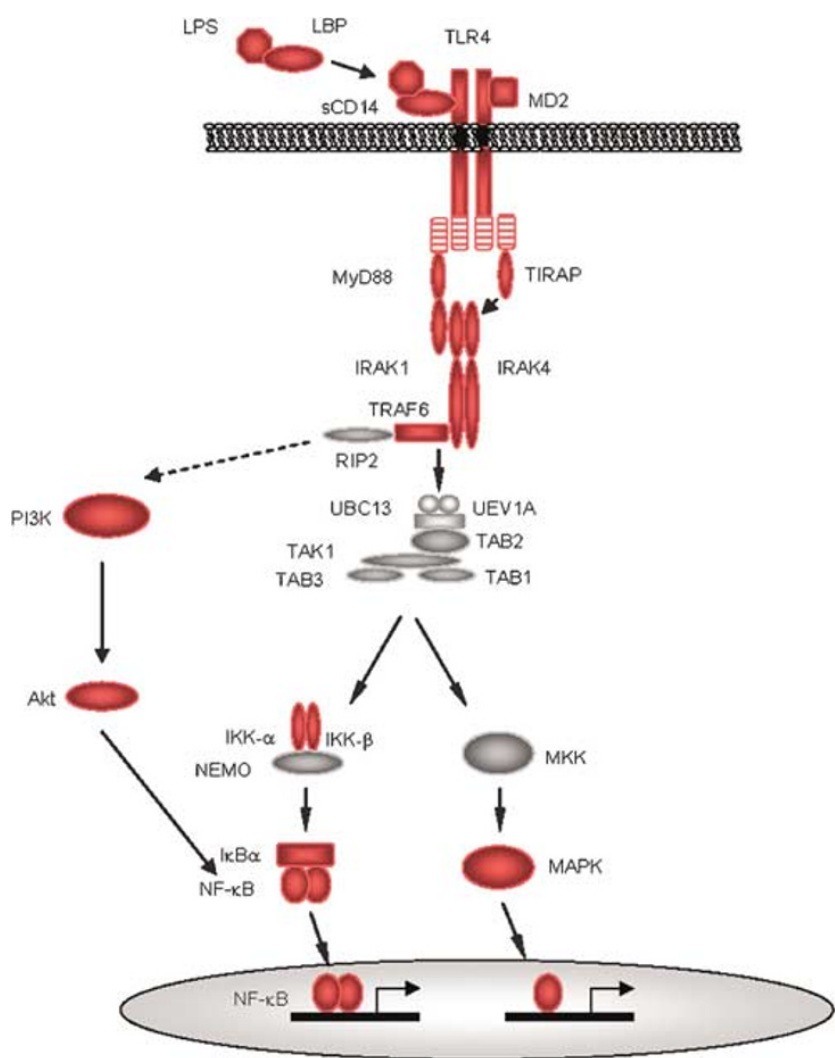

Figure 1 MyD88-dependent signaling pathway. In endothelial cells, LPS binds to the TLR4 receptor complex consisting of soluble CD14 (sCD14) and MD2. This results in the recruitment of the adaptor molecules MyD88 and TIRAP. Then, IRAK1 and 4 are recruited to the receptor complex via interactions between the DDs of MyD88 and IRAKs. IRAK1 recruits and activates TRAF6, leading to the downstream activation of the IKK complex and the MAPKs. Activation of the IKK complex results in phosphorylation and degradation of $\mathrm{I} \kappa \mathrm{B}$, permitting the nuclear translocation of the transcription factor, NF- $\kappa \mathrm{B}$. This results in the expression of proinflammatory molecules. Concurrently, activation of the MAPKs, predominantly JNK, results in activation of the transcription factor AP-1, leading to a proapoptotic state. PI3K, through association with MyD88 or TRAF6, is also involved in $\mathrm{NF}-\kappa \mathrm{B}$ activation through an Akt-dependent mechanism. Molecules which are known to be involved in endothelial TLR4mediated signaling are highlighted in red. 
proliferate in response to LPS, indicating that PI3K plays a role in LPS-induced signaling events. ${ }^{87}$ Following LPS challenge, PI3K has been shown to exist in a complex with TLR4 and MyD88 in murine macrophages. ${ }^{88}$ Consistent with this, enforced expression of various dominant negative mutants has shown that PI3K activation is downstream of MyD88/IRAK/TRAF6, but not TIRAP. ${ }^{89,90}$ Further, PI3K and its downstream target kinase, Akt, appear to be an important component of LPS-induced $\mathrm{NF}-\kappa \mathrm{B}$ activity following its translocation to the nucleus. ${ }^{88,90}$

RIP is a serine/threonine kinase that plays a critical role in LPS-induced activation of NF- $\kappa$ B. ${ }^{91}$ $\mathrm{RIP}^{-1-}$ splenocytes exhibit decreased LPS-induced Akt phosphorylation, suggesting that RIP also connects TLR4 signaling to PI3K activation. ${ }^{91}$ RIP2 is a kinase related to RIP that contains a caspase recruitment domain (CARD) at its N-terminus. ${ }^{92}$ RIP2 knockout mice are resistant to the lethal effects of LPS-induced septic shock ${ }^{93}$ and RIP2 participates in LPS signaling in a kinase independent manner, likely functioning as an adaptor molecule $^{94}$ (Figure 1).

\section{Mitogen-activated protein kinases}

In addition to the activation of $\mathrm{NF}-\kappa \mathrm{B}$ and PI3K, activation of TAK1 also leads to activation of a family of MAPKs consisting of p38, extracellular signal-regulated kinase (ERK) and c-jun $\mathrm{NH}_{2}$-terminal kinase $(\mathrm{JNK})^{79}$ (Figure 1). Activation of the MAPKs by TLR4 involves MyD88 and TIRAP. ${ }^{62}$ However, both MyD88 and TIRAP knockout mice are able to activate MAPKs albeit with delayed kinetics, pointing to the existence of a MyD88/ TIRAP-independent pathway for the activation of MAPKs. ${ }^{65}$ The mechanism of TLR4-mediated activation of MAPKs is not fully understood but it has been recognized that their activation occurs differentially during exposure to LPS.

Activation of p38 is critically dependent on MEKK3. ${ }^{95}$ MEKK3 activates both NF- $\kappa \mathrm{B}$ and p38 kinase, but not ERK, by binding to TRAF6 in mouse embryonic fibroblasts (MEFs) ${ }^{95}$ However, a dominant negative mutant of TRAF6 does not inhibit LPS activation of p38 in endothelial cells, suggesting that p38 does not lie downstream of TRAF6. ${ }^{96}$ Similarly, TRAF6 is not required for LPS-induced activation of ERK in endothelial cells. ${ }^{90}$ Nonetheless, in immune cells, the activation of p38 involves TRAF6 and apoptosis signal-regulating kinase 1 (ASK1). ${ }^{97}$ LPSinduced intracellular reactive oxygen species (ROS) mediate the formation of a complex between TRAF6 and ASK1 to facilitate activation of p38 but not JNK. ${ }^{97}$ Furthermore, ASK1 is required for LPSinduced cytokine production and ASK1-null mice are resistant to endotoxic shock. ${ }^{97}$

The activation of ERK in response to LPS has not been well characterized. However, the MAP kinase kinase, Tpl2 (also known as Cot) has been implicated in LPS-induced ERK activation in macro- phages. ${ }^{98}$ Tpl2 has been shown to coordinate with the Ras pathway to induce activation of ERK in COS1 monkey kidney cells ${ }^{99}$ and the Ras pathway has been implicated in LPS-induced ERK activation. ${ }^{100}$

In endothelial cells, JNK activation has been shown to require TRAF6 activation. ${ }^{96}$ In macrophages, however, activation of JNK is dependent on interaction of the scaffolding protein JNK-interacting protein 3 (JIP3) with the cytoplasmic domain of TLR4. ${ }^{101}$ Inhibition of JIP3 function, either by expression of a dominant negative form of the protein or using RNA interference, inhibits JNK activation in macrophages. ${ }^{101}$ JIP3 is physically associated with MEKK1 in RAW264.7 cells. ${ }^{101}$ In neutrophils, LPS-induced JNK activation involves the participation of the protein tyrosine kinase, Syk, and PI3K. ${ }^{102}$ Taken together, these findings suggest that the receptor complex may include many more proteins than that shown in Figures 1 and 2.

\section{Functional effects of MyD88/TIRAP-dependent signaling}

LPS activates both NF- $\kappa$ B and JNK through TRAF6, leading to proinflammatory and apoptotic signaling pathways, respectively. ${ }^{96}$ TRAF6 is also the bifurcation point, downstream of which both death and survival signals are induced. ${ }^{90}$ We have shown that LPS induces a proapoptotic signal through TRAF6mediated activation of JNK, which in turn leads to caspase activation following mitochondrial depolarization. $^{96}$ Additionally, PI3K-dependent survival signals are mediated downstream of TRAF6 in endothelial cells. ${ }^{90}$ The TRAF6-interacting protein, RIP, is essential for cell survival following LPS stimulation in splenocytes and provides a link between TLR4 and the PI3K-Akt survival pathway. ${ }^{91}$ LPS has also been shown to directly stimulate endothelial sprouting in vitro and angiogenesis in vivo. ${ }^{103}$ The initiation of angiogenesis mediated by LPS is dependent on TRAF6 and the downstream effector molecules, NF- $\kappa$ B and JNK. ${ }^{103}$ The balance between endothelial survival and death pathways is crucial in the pathogenesis of sepsis as endothelial cell apoptosis could potentially lead to severe vascular collapse, as demonstrated by the disseminated endothelial apoptosis seen in C57BL/6 mice challenged with LPS ${ }^{104}$ (Figure 2).

\section{MyD88-Independent Signaling}

The MyD88-independent signaling pathway was identified in studies using MyD88 deficient mice. ${ }^{105}$ Although MyD88 ${ }^{-/}$mice were resistant to LPSinduced death, delayed activation of both NF- $\kappa \mathrm{B}$ and MAPK pathways was observed. ${ }^{105}$ Furthermore, MyD88-deficient cells failed to release proinflammatory cytokines in response to LPS suggesting direct activation of NF- $\kappa \mathrm{B}$ and the MAPKs by LPS. ${ }^{106}$ Collectively, these results suggested the existence of a MyD88-independent pathway downstream of 

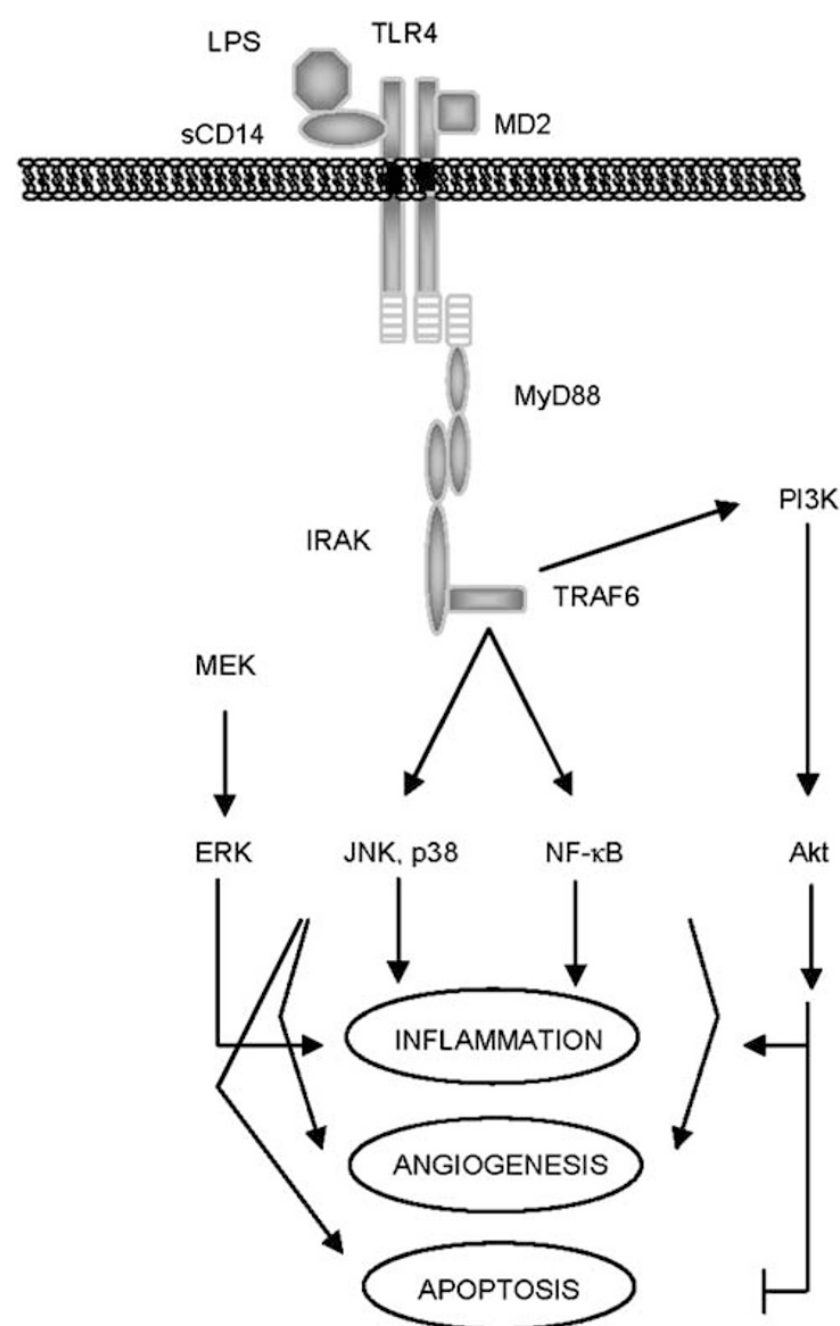

Figure 2 LPS-induced signaling events in endothelial cells. Stimulation of endothelial cells with LPS results in the activation of TRAF6, leading to activation of several downstream signaling pathways, including activation of JNK and NF- $\kappa \mathrm{B}$, leading to the production of proinflammatory signaling molecules. Activation of TRAF6 also results in endothelial sprouting through JNK and NF$\kappa \mathrm{B}$-dependent signaling pathways. Furthermore, activation of TRAF6 also results in the activation of PI3K and Akt, which results in stimulation of inflammation, but inhibition of apoptosis. The activation of ERK in endothelial cells is TRAF6independent.

ligand engagement of the TLR4 receptor. The MyD88-dependent pathway is largely responsible for controlling the expression of inflammatory cytokines, such as TNF $\alpha$, IL-6 and IL-12, through activation of NF- $\kappa \mathrm{B}$, whereas the MyD88-independent pathway induces expression of IFN-inducible genes, such as IP10 and glucocorticoid-attenuated response gene 16 (GARG16), through activation of the transcription factor, IFN regulatory factor 3 (IRF3) ${ }^{107}$ MyD88-independent signaling begins with recruitment of the adaptor molecule, TRAM, to the cytoplasmic domain of TLR4. ${ }^{108}$ TRAM is specific to the TLR4 signaling pathway and was cloned as a TLR4-binding protein in yeast that facilitates the binding of TRIF to the receptor complex by forming
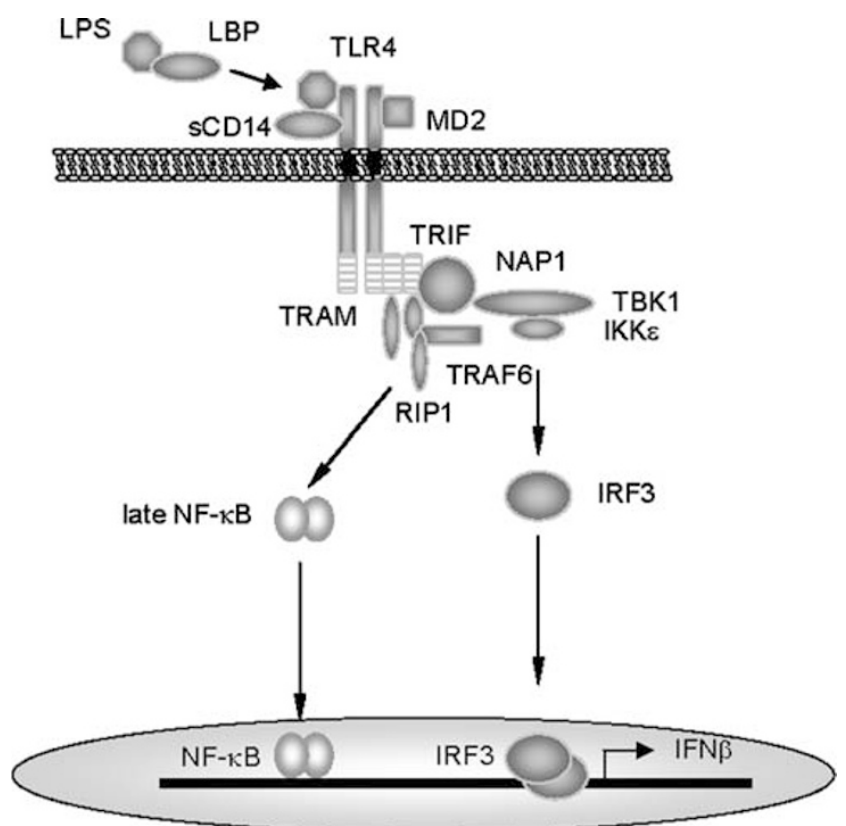

Figure 3 MyD88-independent signaling pathway. The late-phase activation of NF- $\kappa \mathrm{B}$ occurs through the MyD88-independent pathway involving the adaptor molecules, TRIF and TRAM. TRIF associates with TRAF6 and RIP1, as well as NAP1 and TBK1, to lead to the activation of the transcription factors, NF- $\kappa$ B and IRF3, respectively. MyD88-independent signaling has not been extensively studied in endothelial cells.

heterodimers with TRIF. ${ }^{108,109}$ TRIF has been shown to play an essential role in IRF3 activation and production of IFN $\beta .{ }^{110}$ The recruitment of these adaptor molecules to the receptor complex results in binding of TRAF6 and RIP1 to TRIF, leading to the late-phase activation of $\mathrm{NF}-\kappa \mathrm{B}$, which contributes to the induction of IFN $\beta .^{111}$ In a parallel pathway, TRAF family member-associated NF- $\kappa$ B activator (TANK) binding kinase 1 (TBK1) and $\mathrm{IKK} \varepsilon$ (also known as IKKi) interact with TRIF and mediate activation of IRF3, leading to the induction of IFN $\beta .{ }^{112}$ IRF3 is a member of a family of transcription factors that are involved in the induction of type I IFNs that translocate to the nucleus upon phosphorylation and dimerization. ${ }^{113}$ Once inside the nucleus, IRF3 controls IFN $\beta$ transcription by recruiting the coactivators, p300 and CBP. ${ }^{113} \mathrm{NF}-\kappa \mathrm{B}-$ activating kinase associating protein (NAP1) also interacts with TRIF and TBK1 to stimulate IFN $\beta$ production through activation of IRF3. ${ }^{114}$ Although MyD88-independent pathways have not been directly studied in the endothelium, recent studies have demonstrated LPS-dependent induction of MyD88-independent genes (eg, IFN $\beta$, IP10, IL-6 and iNOS) in endothelial cells ${ }^{115}$ (Figure 3).

\section{Negative regulation of TLR4 signaling}

Modulation of signaling cascades involved in immune regulation is imperative for the prevention 


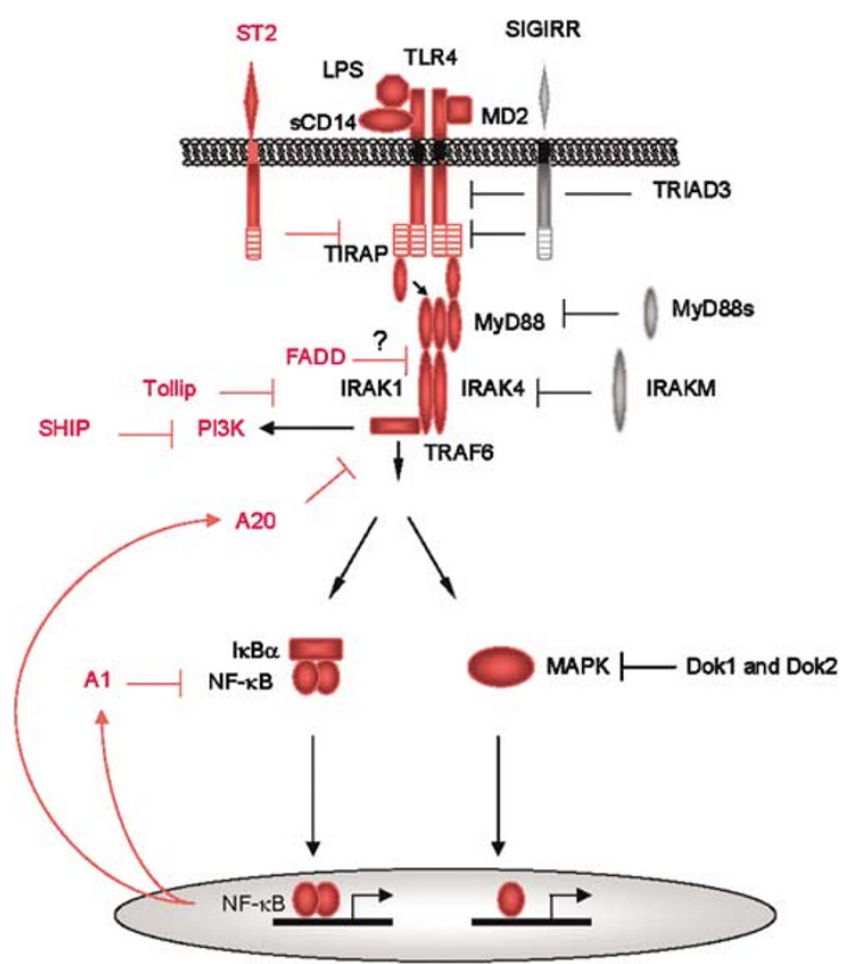

Figure 4 Modulation of TLR4-mediated signaling pathway. TLR4 signaling is regulated by several molecules. In endothelial cells, A20 functions as a deubiquitinase enzyme to inhibit activation of TRAF6 upstream of NF- $\kappa$ B. A1 also inhibits NF- $\kappa$ B activation through an unknown mechanism. Both $\mathrm{A} 1$ and $\mathrm{A} 20$ are upregulated by LPS through NF- $\kappa \mathrm{B}$, suggesting a negative feedback loop to reduce the signaling by LPS. SHIP inhibits PI3K activity. PI3K itself plays a dual role in regulating LPS-induced signaling events, acting as both a positive and a negative regulator. FADD attenuates the activation of $\mathrm{NF}-\kappa \mathrm{B}$, perhaps by sequestering MyD88 or IRAK to prevent downstream signaling. ST2, an orphan receptor expressed in endothelial cells, sequesters the adaptor molecules MyD88 and TIRAP, preventing downstream signaling. In nonendothelial cells, a splice variant of MyD88, MyD88s, inhibits the association of MyD88 and IRAK. IRAKM prevents the association of IRAK and TRAF6. The orphan receptor, SIGIRR, negatively regulates TLR signaling, possibly by attenuating the recruitment of downstream signaling molecules. Dok1 and Dok2 inhibit LPS-induced ERK activation. Molecules that are involved in endothelial TLR4-mediated signaling, or implicated in the regulation of this pathway, are highlighted in red.

of an aberrant inflammatory response. Several molecules have been identified that regulate the TLR4 signaling pathway (Figure 4).

\section{Downstream of Tyrosine Kinases (Dok)}

Dok proteins are a family of adaptor proteins, consisting of Dok-1-5. ${ }^{116-119}$ Dok1 and Dok2 have been reported to be involved in the negative regulation of LPS signaling. ${ }^{120}$ Mice that are deficient in Dok1 and Dok2 show an increase in TNF $\alpha$ and NO production in peritoneal and bone-marrow derived macrophages, as compared to wild-type cells. ${ }^{120}$ Furthermore, these mice exhibit an in- creased sensitivity to LPS, as demonstrated by an increase in $\mathrm{TNF} \alpha$ production and increased lethality compared to wild-type mice. ${ }^{120}$ Overexpression of Dok1 or Dok2 inhibits LPS-induced ERK activation. ${ }^{120}$ Dok4 is highly expressed in endothelial cells $^{121}$ and has recently been implicated as a positive regulator of TNF $\alpha$-mediated NF- $\kappa$ B activation in endothelial cells. ${ }^{122}$ However, the Dok family has not been studied in the LPS response of endothelial cells.

\section{Phosphatidylinositol 3-Kinase}

PI3K plays a dual role in LPS signaling events as it is both positively and negatively involved in TLR signal transduction. PI3K has been shown to negatively regulate the production of inflammatory mediators important in the pathogenesis of sepsis, such as proinflammatory cytokines and NO. ${ }^{123,124}$ In endothelial cells and monocytes, inhibition of the PI3K-Akt pathway has been shown to enhance LPSinduced cytokine production, suggesting a negative regulatory role for PI3K. ${ }^{125}$ Activation of PI3K also reduces MyD88-dependent production of the proinflammatory molecules IL-12 in dendritic cells and TNF $\alpha$ in monocytes. ${ }^{126,127}$ In C6 glial cells stimulated with LPS, inhibition of PI3K results in the induction of NOS. ${ }^{123}$ Moreover, the enforced expression of a constitutively active form of PI3K has been shown to inhibit the expression of NOS2 in human astrocytes. ${ }^{128}$ Collectively, these results demonstrate that PI3K is a negative regulator of NO production in several cell types.

Conversely, PI3K has been shown to positively regulate MyD88-dependent signaling through the TLR2 receptor, although whether this is true in endothelial cells has not been studied. Inhibition of PI3K leads to a reduction in the activation of NF- $\kappa \mathrm{B}$ and the MAPKs, p38 and p44/42. ${ }^{129}$ PI3K also plays a role in MyD88-independent signaling. In the TRIFdependent signaling cascade, PI3K physically associates with TRIF in response to LPS and inhibits TRIF-dependent NF- $\kappa \mathrm{B}$ transcriptional activity, but has no effect on IRF3 activation in dendritic cells. ${ }^{130}$

A20

A20 is a zinc-finger protein that was initially identified as an antiapoptotic protein, but has subsequently been shown to have both ubiquitinase and deubiquitinase activities. ${ }^{131-133}$ In endothelial cells, expression of A20 is induced by LPS in a sCD14- and NF- $\kappa$ B-dependent manner. ${ }^{134}$ Mice that are deficient for the expression of A20 exhibit increased responsiveness to LPS and develop severe inflammation. ${ }^{135}$ Expression of A20 inhibits TLR4mediated NF- $\kappa \mathrm{B}$ activation by regulating MEKK-1 kinase activity. ${ }^{136}$ The regulatory action imparted by A20 is dependent on its ability to act as a TRAF6 deubiquitinase, thereby reversing TRAF6 
activation. ${ }^{137}$ A20 also acts as a negative regulator of $\mathrm{TNF} \alpha$-induced NF- $\kappa \mathrm{B}$ activation through ubiquitination of RIP, targeting RIP for degradation. ${ }^{132}$ Whether A20 also regulates LPS signaling by ubiquitinating RIP remains to be shown. The upregulation of A20 by LPS suggests that A20 functions as part of a negative feedback mechanism to regulate the innate immune response to LPS.

\section{A1}

A1 is a homolog of the antiapoptotic molecule, Bcl2 , that also functions as a cytoprotective protein in response to TNF stimulation. ${ }^{134,138}$ Similar to A20, LPS upregulates mRNA expression of A1 in endothelial cells through an NF- $\kappa \mathrm{B}$-dependent mechanism, ${ }^{134}$ and protects cells from LPS-induced apoptosis. In addition to the antiapoptotic effects of A1, it has also been shown that the Bcl homology 4 (BH4) domain of A1 inhibits endothelial activation by inhibiting NF- $\kappa \mathrm{B}$ activity, and thus one of the major proinflammatory pathways activated by LPS. ${ }^{139,140}$ Thus, the NF- $\kappa \mathrm{B}$-dependent upregulation of A1 by LPS acts as a negative regulator in a feedback loop to dampen the LPS signal.

\section{Fas-Associated Death Domain (FADD)}

FADD is a proapoptotic adaptor molecule that couples the cytoplasmic domain of death receptor molecules to effector caspases. ${ }^{141}$ Prior to identification of mammalian TLRs, we had shown that LPS regulates apoptosis through a FADD-dependent pathway that was independent of death receptor signaling. ${ }^{142}$ More recently, FADD has been shown to play an inhibitory role in LPS-induced NF- $\kappa \mathrm{B}$ dependent gene expression. FADD ${ }^{-1-}$ MEFs stimulated with LPS demonstrate increased I $\kappa$ B- $\beta$ degradation compared to $\mathrm{FADD}^{+/+}$cells, indicating that the role of FADD is upstream of $\mathrm{I} \kappa \mathrm{B}$ degradation. ${ }^{143}$ Although a definitive role for FADD in LPS signaling has been established, the mechanism through which FADD exerts its effects remains unclear. MyD88 is a mediator of TLR2-induced apoptosis through a FADD-dependent pathway through the binding of FADD to the DD of MyD88 and subsequent recruitment of caspase $8 .{ }^{144}$ As such, it has been suggested that, during LPS signaling, FADD may bind to the DD of MyD88 and thereby prevent the obligatory interaction between MyD88 and IRAK. ${ }^{143}$ Similarly, it is also possible that FADD binds to IRAK to sequester it in the cytosol, thus preventing the interaction with MyD88 and subsequently abrogating downstream signaling events.

\section{Toll-Interacting Protein (Tollip)}

Tollip was identified as a protein partner of the IL1R complex following IL-1 stimulation. In unstimu- lated cells, Tollip forms a complex with IRAK and is recruited to the receptor following stimulation. ${ }^{145}$ Tollip has also been shown to associate with TLR4 and is phosphorylated by IRAK following stimulation with LPS. ${ }^{146}$ Tollip plays a negative role in LPS signaling in macrophages by suppressing the activity of IRAK before receptor activation. ${ }^{146}$ Furthermore, overexpression of Tollip results in the inhibition of NF- $\kappa$ B activity downstream of IRAK. ${ }^{145}$ Tollip is expressed in human dermal endothelial cells and ectopic expression of Tollip in these cells inhibits LPS-induced NF- $\kappa$ B activation. ${ }^{147}$

\section{Src Homology 2 Domain-Containing Inositol-5-Phosphate (SHIP)}

SHIP is a cellular phosphatase that catalyzes the removal of a phosphate group from PtdIns 3,4,5triphosphate, a product of PI3K activity. ${ }^{148}$ Upon initial exposure to LPS, intracellular levels of SHIP are increased, which promotes endotoxin tolerance. ${ }^{149}$ SHIP1 negatively regulates LPS-induced activation of Akt downstream of PI3K. In addition, SHIP1 also inhibits LPS-induced MAPK activation and $\mathrm{I} \kappa \mathrm{B}-\alpha$ degradation, although this is independent of PI3K involvement. However, this function is thought to occur by SHIP inhibiting formation of a complex between TLR4 and MyD88. ${ }^{150}$ SHIP1 is expressed in endothelial cells, ${ }^{151}$ and thus may play a role in the regulation of LPS signaling in these cells.

\section{ST2}

ST2 (also known as T1) is a TIR-domain-containing orphan receptor expressed on TH2 cells and mast cells. ${ }^{152,153}$ Mice that are deficient for ST2 exhibit an increase in LPS-induced cytokine production. ${ }^{154}$ Although ST2 contains a TIR domain and is able to activate JNK, ERK and p38, it is unable to activate NF- $\kappa$ B. ${ }^{154}$ Forced overexpression of ST2 in HEK293 cells results in a decrease in LPS-induced NF- $\kappa \mathrm{B}$ activation. ${ }^{155}$ The inhibitory effect of ST2 is the result of the interaction between its TIR domain and the TIR domains of MyD88 and TIRAP, thus sequestering these critical adaptors during LPS signaling. ${ }^{154}$ A soluble ST2 receptor was immunoprecipitated from endothelial cells, indicating that ST2 is expressed in these cells. ${ }^{156}$ The presence of ST2 in endothelial cells suggests that this molecule may also be involved in the regulation of TLR4mediated signaling in these cells.

\section{Additional Inhibitors of TLR4 Signaling}

The suppressors of cytokine signaling are a family of intracellular proteins that regulate cytokine signaling in a classical feedback mechanism. ${ }^{157}$ LPSinduced upregulation of the SOCS1 protein has 
been observed in a macrophage cell line and SOCS1 $^{-1-}$ mice are hyperresponsive to LPS, showing increased serum $\mathrm{TNF} \alpha$ levels and increased lethality. ${ }^{158}$ Furthermore, ectopic expression of SOCS1 in a macrophage cell line inhibits LPSinduced NF- $\kappa$ B activation. ${ }^{158,159}$ SOCS1 is expressed in endothelial cells, ${ }^{160}$ but its involvement in regulating LPS signaling in these cells has not been examined.

RP105 is a TLR homolog that lacks an intracellular TIR domain. ${ }^{161}$ Expression of RP105 is induced in the presence of the MD2 homolog, MD1. ${ }^{162}$ The complex of RP105 and MD1 interacts with TLR4/ MD2, impairing its ability to bind LPS. ${ }^{161}$ Moreover, dendritic cells derived from RP105-deficient mice produce higher levels of proinflammatory cytokines following LPS stimulation, compared to wild-type controls. ${ }^{161}$ Enforced expression of TLR4, MD1 and MD2 in HEK293 cells showed that RP105-mediated inhibition of IL-8 production was the result of inhibition of NF- $\kappa \mathrm{B}$ activity. ${ }^{161} \mathrm{RP} 105$ expression in endothelial cells is low, suggesting that RP105 may play only a minor role in TLR4-mediated signaling in the endothelium. ${ }^{163}$

The chemokine receptor CXCR4 plays a putative role in LPS signaling as part of a proposed LPS activation cluster. ${ }^{49}$ Inhibition of CXCR4 in HEK293 cells expressing TLR4, MD2 and CD14, using antiCXCR4 antibodies, resulted in an increase in NF- $\kappa \mathrm{B}$ luciferase activity in response to LPS, suggesting that CXCR4 inhibits signaling through TLR4. ${ }^{164}$ CXCR4 is expressed in endothelial cells ${ }^{165}$ and thus may be involved in regulating endothelial responses to LPS.

Single immunoglobulin IL-1 receptor-related molecule (SIGIRR) (also known as TIR8) is another member of the TIR-domain-containing receptor family that is unable to induce inflammatory responses. SIGIRR is thought to play a role in regulation of inflammatory events as its expression is downregulated in tissues of mice injected with LPS. ${ }^{166}$ Furthermore, the role of SIGIRR in LPS signaling is thought to be negative, since it interacts with both TLR4 and TRAF6. ${ }^{166}$ SIGIRR has recently been shown to interact with TLR4 through its TIR domain to attenuate recruitment of downstream signaling molecules. ${ }^{167}$ Although SIGIRR functions as a modulator of TLR signaling, expression of SIGIRR is relatively low in endothelial compared with epithelial cell lines, suggesting that it may play only a minimal role in signaling in the endothelium. ${ }^{166}$

Using a yeast two-hybrid approach, TRIAD3 was identified as a RING-finger protein that interacts with the cytoplasmic tail of several TLRs, including TLR4. ${ }^{168}$ The most abundant isoform identified in a range of cell lines is TRIAD3A, which contains structural features reminiscent of an E3 ubiquitinprotein ligase and promotes degradation of the receptor by targeting the receptor for ubiquitination and proteolytic degradation. ${ }^{168}$ Furthermore, deple- tion of intracellular TRIAD3A results in an increase in TLR4-stimulated NF- $\kappa$ B luciferase activity. ${ }^{168}$ TRIAD3A expression has not been examined in endothelial cells.

MyD88s is a splice variant of MyD88 that lacks the intermediate domain required for recruitment of IRAK4. ${ }^{169}$ MyD88s inhibits TLR4 signaling by preventing the recruitment of IRAK4 to MyD88 in the receptor complex, thus abolishing phosphorylation and activation of IRAK1. ${ }^{67}$ As a result, MyD88s functions as a dominant-negative inhibitor and is unable to activate NF- $\kappa \mathrm{B}$. However, activation of JNK is unaffected by MyD88s expression, suggesting that pathways leading to NF- $\kappa \mathrm{B}$ and MAPK activation may diverge at the level of MyD88. ${ }^{170}$ MyD88s expression has not been determined in endothelial cells.

IRAK-M is a functional member of the IRAK/Pelle family that is expressed exclusively in monocytic cell lines. IRAK-M can interact with both MyD88 and TRAF6 and possesses intrinsic kinase activity, although it is incapable of autophosphorylation. ${ }^{\text {171 }}$ IRAK-M plays a negative role in TLR4 signaling by preventing the dissociation of IRAK4 and MyD88 and thus preventing the formation of the IRAKTRAF6 complex. Furthermore, IRAK-M knockout mice show an increased responsiveness to bacterial LPS. ${ }^{172}$

\section{Conclusion}

The mechanism of LPS-induced signaling events mediated by TLR4 has been extensively studied over recent years. Much work has been carried out to elucidate the role of specific molecules comprising the signaling pathways and to identify the negative regulators of the LPS signaling cascades such that therapeutic approaches may be derived from these discoveries. Novel players involved in TLR4 signal transduction, such as Nod1 and Nod2, ${ }^{173}$ as well as the demonstration of crosstalk interactions with other signaling pathways, such as those seen between TGF $\beta^{174}$ and TLR4 signaling cascades, will provide further insight into the molecular mechanisms of innate immunity.

Although research in the field of TLR signaling has predominantly focused on the pathways initiated in macrophages and monocytes, it is evident that the endothelium plays a critical role during sepsis. A deeper understanding of the regulatory elements of TLR4-mediated survival and death pathways in endothelial cells may facilitate the development of novel therapies to avoid the pathological events associated with endothelial injury during sepsis.

\section{References}

1 Angus DC, Linde-Zwirble WT, Lidicker J, et al. Epidemiology of severe sepsis in the United States: 
analysis of incidence, outcome, and associated costs of care. Crit Care Med 2001;29:1303-1310.

2 Pinsky MR. Dysregulation of the immune response in severe sepsis. Am J Med Sci 2004;328:220-229.

3 Medzhitov R. Toll-like receptors and innate immunity. Nat Rev Immunol 2001;1:135-145.

4 Jaffe EA. Cell biology of endothelial cells. Hum Pathol 1987;18:234-239.

5 Grandel U, Grimminger F. Endothelial responses to bacterial toxins in sepsis. Crit Rev Immunol 2003; 23:267-299.

6 Volk T, Kox WJ. Endothelium function in sepsis. Inflamm Res 2000;49:185-198.

7 Salgado A, Boveda JL, Monasterio J, et al. Inflammatory mediators and their influence on haemostasis. Haemostasis 1994;24:132-138.

8 Sumpio BE, Riley JT, Dardik A. Cells in focus: endothelial cell. Int J Biochem Cell Biol 2002;34: 1508-1512.

9 Rongen GA, Smits P, Thien T. Endothelium and the regulation of vascular tone with emphasis on the role of nitric oxide. Physiology, pathophysiology and clinical implications. Neth J Med 1994;44:26-35.

10 Ruschitzka F, Corti R, Noll G, et al. A rationale for treatment of endothelial dysfunction in hypertension. J Hypertens Suppl 1999;17:S25-S35.

11 Morikawa A, Koide N, Kato Y, et al. Augmentation of nitric oxide production by gamma interferon in a mouse vascular endothelial cell line and its modulation by tumor necrosis factor alpha and lipopolysaccharide. Infect Immun 2000;68:6209-6214.

12 Petros A, Bennett D, Vallance P. Effect of nitric oxide synthase inhibitors on hypotension in patients with septic shock. Lancet 1991;338:1557-1558.

13 Spohr F, Cornelissen AJ, Busch C, et al. Role of endogenous nitric oxide in endotoxin-induced alteration of hypoxic pulmonary vasoconstriction in mice. Am J Physiol Heart Circ Physiol 2005;289: H823-H831.

14 Thiemermann C. Nitric oxide and septic shock. Gen Pharmacol 1997;29:159-166.

15 Yuan SY. Protein kinase signaling in the modulation of microvascular permeability. Vascul Pharmacol 2002;39:213-223.

16 Bannerman DD, Fitzpatrick MJ, Anderson DY, et al. Endotoxin-neutralizing protein protects against endotoxin-induced endothelial barrier dysfunction. Infect Immun 1998;66:1400-1407.

17 Bannerman DD, Sathyamoorthy M, Goldblum SE. Bacterial lipopolysaccharide disrupts endothelial monolayer integrity and survival signaling events through caspase cleavage of adherens junction proteins. J Biol Chem 1998;273:35371-35380.

18 Kubes P. The complexities of leukocyte recruitment. Semin Immunol 2002;14:65-72.

19 Ulbrich H, Eriksson EE, Lindbom L. Leukocyte and endothelial cell adhesion molecules as targets for therapeutic interventions in inflammatory disease. Trends Pharmacol Sci 2003;24:640-647.

20 Lush CW, Cepinskas G, Kvietys PR. LPS tolerance in human endothelial cells: reduced PMN adhesion, E-selectin expression, and NF-kappaB mobilization. Am J Physiol Heart Circ Physiol 2000;278:H853H861.

21 Boyle Jr EM, Kovacich JC, Canty Jr TG, et al. Inhibition of nuclear factor-kappa B nuclear localization reduces human E-selectin expression and the systemic inflammatory response. Circulation 1998; 98:II282-II288.

22 Collins T, Read MA, Neish AS, et al. Transcriptional regulation of endothelial cell adhesion molecules: NF-kappa B and cytokine-inducible enhancers. FASEB J 1995;9:899-909.

23 Cummings CJ, Sessler CN, Beall LD, et al. Soluble Eselectin levels in sepsis and critical illness. Correlation with infection and hemodynamic dysfunction. Am J Respir Crit Care Med 1997;156:431-437.

24 Matsukawa A, Lukacs NW, Hogaboam CM, et al. Mice genetically lacking endothelial selectins are resistant to the lethality in septic peritonitis. Exp Mol Pathol 2002;72:68-76.

$25 \mathrm{Wu} \mathrm{KK}$, Thiagarajan P. Role of endothelium in thrombosis and hemostasis. Annu Rev Med 1996;47: 315-331.

26 Dahlback B, Villoutreix BO. The anticoagulant protein C pathway. FEBS Lett 2005;579:3310-3316.

27 Moore KL, Andreoli SP, Esmon NL, et al. Endotoxin enhances tissue factor and suppresses thrombomodulin expression of human vascular endothelium in vitro. J Clin Invest 1987;79:124-130.

28 Pawlinski R, Mackman N. Tissue factor, coagulation proteases, and protease-activated receptors in endotoxemia and sepsis. Crit Care Med 2004;32:S293S297.

29 Parry GC, Mackman N. Transcriptional regulation of tissue factor expression in human endothelial cells. Arterioscler Thromb Vasc Biol 1995;15:612-621.

30 Alexander C, Rietschel ET. Bacterial lipopolysaccharides and innate immunity. J Endotoxin Res 2001;7: 167-202.

31 Hack CE, Zeerleder S. The endothelium in sepsis: source of and a target for inflammation. Crit Care Med 2001;29:S21-S27.

32 Slack JL, Schooley K, Bonnert TP, et al. Identification of two major sites in the type I interleukin-1 receptor cytoplasmic region responsible for coupling to proinflammatory signaling pathways. J Biol Chem 2000; 275:4670-4678.

33 Tabeta K, Georgel P, Janssen E, et al. Toll-like receptors 9 and 3 as essential components of innate immune defense against mouse cytomegalovirus infection. Proc Natl Acad Sci USA 2004;101: 3516-3521.

34 Chuang TH, Ulevitch RJ. Cloning and characterization of a sub-family of human toll-like receptors: hTLR7, hTLR8 and hTLR9. Eur Cytokine Netw 2000;11:372-378.

35 Chuang T, Ulevitch RJ. Identification of hTLR10: a novel human Toll-like receptor preferentially expressed in immune cells. Biochim Biophys Acta 2001;1518:157-161.

$36 \mathrm{Du}$ X, Poltorak A, Wei Y, et al. Three novel mammalian toll-like receptors: gene structure, expression, and evolution. Eur Cytokine Netw 2000; 11:362-371.

37 Poltorak A, He X, Smirnova I, et al. Defective LPS signaling in $\mathrm{C} 3 \mathrm{H} / \mathrm{HeJ}$ and $\mathrm{C} 57 \mathrm{BL} / 10 \mathrm{ScCr}$ mice: mutations in Tlr4 gene. Science 1998;282: 2085-2088.

38 Darveau RP, Pham TT, Lemley K, et al. Porphyromonas gingivalis lipopolysaccharide contains multiple lipid A species that functionally interact with both toll-like receptors 2 and 4. Infect Immun 2004;72: 5041-5051. 
39 Schumann RR, Leong SR, Flaggs GW, et al. Structure and function of lipopolysaccharide binding protein. Science 1990;249:1429-1431.

40 Dunzendorfer S, Lee HK, Soldau K, et al. TLR4 is the signaling but not the lipopolysaccharide uptake receptor. J Immunol 2004;173:1166-1170.

41 da Silva Correia J, Soldau K, Christen U, et al. Lipopolysaccharide is in close proximity to each of the proteins in its membrane receptor complex. transfer from CD14 to TLR4 and MD-2. J Biol Chem 2001;276:21129-21135

42 Wright SD. CD14 and innate recognition of bacteria. J Immunol 1995;155:6-8.

43 Arditi M, Zhou J, Dorio R, et al. Endotoxin-mediated endothelial cell injury and activation: role of soluble CD14. Infect Immun 1993;61:3149-3156.

44 Bufler P, Stiegler G, Schuchmann M, et al. Soluble lipopolysaccharide receptor (CD14) is released via two different mechanisms from human monocytes and CD14 transfectants. Eur J Immunol 1995;25: 604-610.

45 Jersmann HP, Hii CS, Hodge GL, et al. Synthesis and surface expression of CD14 by human endothelial cells. Infect Immun 2001;69:479-485.

46 Pugin J, Schurer-Maly CC, Leturcq D, et al. Lipopolysaccharide activation of human endothelial and epithelial cells is mediated by lipopolysaccharidebinding protein and soluble CD14. Proc Natl Acad Sci USA 1993;90:2744-2748.

47 Nagai Y, Akashi S, Nagafuku M, et al. Essential role of MD-2 in LPS responsiveness and TLR4 distribution. Nat Immunol 2002;3:667-672.

48 Visintin A, Latz E, Monks BG, et al. Lysines 128 and 132 enable lipopolysaccharide binding to $\mathrm{MD}-2$, leading to Toll-like receptor-4 aggregation and signal transduction. J Biol Chem 2003;278:48313-48320.

49 Triantafilou M, Triantafilou K. Lipopolysaccharide recognition: CD14, TLRs and the LPS-activation cluster. Trends Immunol 2002;23:301-304.

50 Triantafilou K, Triantafilou M, Dedrick RL. A CD14independent LPS receptor cluster. Nat Immunol 2001;2:338-345.

51 Dunzendorfer S, Lee HK, Soldau K, et al. Toll-like receptor 4 functions intracellularly in human coronary artery endothelial cells: roles of LBP and sCD14 in mediating LPS responses. FASEB J 2004;18: 1117-1119.

52 Hornef MW, Frisan T, Vandewalle A, et al. Toll-like receptor 4 resides in the Golgi apparatus and colocalizes with internalized lipopolysaccharide in intestinal epithelial cells. J Exp Med 2002;195: 559-570.

53 Hornef MW, Normark BH, Vandewalle A, et al. Intracellular recognition of lipopolysaccharide by toll-like receptor 4 in intestinal epithelial cells. J Exp Med 2003;198:1225-1235.

54 Shnyra A, Lindberg AA. Scavenger receptor pathway for lipopolysaccharide binding to Kupffer and endothelial liver cells in vitro. Infect Immun 1995; 63:865-873.

55 Latz E, Visintin A, Lien E, et al. Lipopolysaccharide rapidly traffics to and from the Golgi apparatus with the toll-like receptor 4-MD-2-CD14 complex in a process that is distinct from the initiation of signal transduction. J Biol Chem 2002;277:47834-47843.

56 Triantafilou M, Miyake K, Golenbock DT, et al. Mediators of innate immune recognition of bacteria concentrate in lipid rafts and facilitate lipopolysaccharide-induced cell activation. J Cell Sci 2002;115: 2603-2611.

57 Zhang H, Tay PN, Cao W, et al. Integrin-nucleated Toll-like receptor (TLR) dimerization reveals subcellular targeting of TLRs and distinct mechanisms of TLR4 activation and signaling. FEBS Lett 2002;532: 171-176.

58 Lee HK, Dunzendorfer S, Tobias PS. Cytoplasmic domain-mediated dimerizations of toll-like receptor 4 observed by beta-lactamase enzyme fragment complementation. J Biol Chem 2004;279:10564-10574.

59 Akira S, Takeda K. Toll-like receptor signalling. Nat Rev Immunol 2004;4:499-511.

60 Takeda K, Akira S. TLR signaling pathways. Semin Immunol 2004;16:3-9.

61 Wesche H, Henzel WJ, Shillinglaw W, et al. MyD88: an adapter that recruits IRAK to the IL-1 receptor complex. Immunity 1997;7:837-847.

62 O’Neill LA, Dunne A, Edjeback M, et al. Mal and MyD88: adapter proteins involved in signal transduction by Toll-like receptors. J Endotoxin Res 2003;9: 55-59.

63 Li S, Strelow A, Fontana EJ, et al. IRAK-4: a novel member of the IRAK family with the properties of an IRAK-kinase. Proc Natl Acad Sci USA 2002;99: 5567-5572.

64 Fitzgerald KA, Palsson-McDermott EM, Bowie AG, et al. Mal (MyD88-adapter-like) is required for Tolllike receptor-4 signal transduction. Nature 2001;413: 78-83.

65 Yamamoto M, Sato S, Hemmi H, et al. Essential role for TIRAP in activation of the signalling cascade shared by TLR2 and TLR4. Nature 2002;420:324-329.

66 Bannerman DD, Erwert RD, Winn RK, et al. TIRAP mediates endotoxin-induced NF-kappaB activation and apoptosis in endothelial cells. Biochem Biophys Res Commun 2002;295:157-162.

67 Burns K, Janssens S, Brissoni B, et al. Inhibition of interleukin 1 receptor/Toll-like receptor signaling through the alternatively spliced, short form of MyD88 is due to its failure to recruit IRAK-4. J Exp Med 2003;197:263-268.

68 Suzuki N, Suzuki S, Duncan GS, et al. Severe impairment of interleukin-1 and Toll-like receptor signalling in mice lacking IRAK-4. Nature 2002;416: 750-756.

69 Cao Z, Xiong J, Takeuchi M, et al. TRAF6 is a signal transducer for interleukin-1. Nature 1996;383: 443-446.

70 Chung JY, Park YC, Ye H, et al. All TRAFs are not created equal: common and distinct molecular mechanisms of TRAF-mediated signal transduction. J Cell Sci 2002;115:679-688.

71 Jiang Z, Ninomiya-Tsuji J, Qian Y, et al. Interleukin-1 (IL-1) receptor-associated kinase-dependent IL-1induced signaling complexes phosphorylate TAK1 and TAB2 at the plasma membrane and activate TAK1 in the cytosol. Mol Cell Biol 2002;22:7158-7167.

72 Shibuya H, Yamaguchi K, Shirakabe K, et al. TAB1: an activator of the TAK1 MAPKKK in TGF-beta signal transduction. Science 1996;272:1179-1182.

73 Takaesu G, Kishida S, Hiyama A, et al. TAB2, a novel adaptor protein, mediates activation of TAK1 MAPKKK by linking TAK1 to TRAF6 in the IL-1 signal transduction pathway. Mol Cell 2000;5: 649-658. 
74 Kishida S, Sanjo H, Akira S, et al. TAK1-binding protein 2 facilitates ubiquitination of TRAF6 and assembly of TRAF6 with IKK in the IL-1 signaling pathway. Genes Cells 2005;10:447-454.

75 Cheung PC, Nebreda AR, Cohen P. TAB3, a new binding partner of the protein kinase TAK1. Biochem J 2004;378:27-34.

76 Deng L, Wang C, Spencer E, et al. Activation of the IkappaB kinase complex by TRAF6 requires a dimeric ubiquitin-conjugating enzyme complex and a unique polyubiquitin chain. Cell 2000;103: 351-361.

77 Yamin TT, Miller DK. The interleukin-1 receptorassociated kinase is degraded by proteasomes following its phosphorylation. J Biol Chem 1997;272: 21540-21547.

78 Jensen LE, Whitehead AS. Ubiquitin activated tumor necrosis factor receptor associated factor-6 (TRAF6) is recycled via deubiquitination. FEBS Lett 2003;553: 190-194.

79 Wang C, Deng L, Hong M, et al. TAK1 is a ubiquitindependent kinase of MKK and IKK. Nature 2001;412: 346-351.

80 Ea CK, Sun L, Inoue J, et al. TIFA activates IkappaB kinase (IKK) by promoting oligomerization and ubiquitination of TRAF6. Proc Natl Acad Sci USA 2004;101:15318-15323.

81 Chen Z, Hagler J, Palombella VJ, et al. Signal-induced site-specific phosphorylation targets I kappa B alpha to the ubiquitin-proteasome pathway. Genes Dev 1995;9:1586-1597.

82 Zen K, Karsan A, Eunson T, et al. Lipopolysaccharide-induced $^{\mathrm{NFkappaB}}$ activation in human endothelial cells involves degradation of IkappaBalpha but not IkappaBbeta. Exp Cell Res 1998;243:425-433.

83 Asehnoune K, Strassheim D, Mitra S, et al. Involvement of PKCalpha/beta in TLR4 and TLR2 dependent activation of NF-kappaB. Cell Signal 2005;17: 385-394.

84 Dallot E, Mehats C, Oger S, et al. A role for PKCzeta in the LPS-induced translocation NF-kappaB p65 subunit in cultured myometrial cells. Biochimie 2005;87: 513-521.

85 Wymann MP, Pirola L. Structure and function of phosphoinositide 3-kinases. Biochim Biophys Acta 1998;1436:127-150.

86 Franke TF, Yang SI, Chan TO, et al. The protein kinase encoded by the Akt proto-oncogene is a target of the PDGF-activated phosphatidylinositol 3-kinase. Cell 1995;81:727-736.

87 Fruman DA, Snapper SB, Yballe CM, et al. Impaired B cell development and proliferation in absence of phosphoinositide 3-kinase p85alpha. Science 1999; 283:393-397.

88 Ojaniemi M, Glumoff V, Harju K, et al. Phosphatidylinositol 3-kinase is involved in Toll-like receptor 4mediated cytokine expression in mouse macrophages. Eur J Immunol 2003;33:597-605.

89 Li X, Tupper JC, Bannerman DD, et al. Phosphoinositide 3 kinase mediates Toll-like receptor 4-induced activation of NF-kappa B in endothelial cells. Infect Immun 2003;71:4414-4420.

90 Wong F, Hull C, Zhande R, et al. Lipopolysaccharide initiates a TRAF6-mediated endothelial survival signal. Blood 2004;103:4520-4526.

91 Vivarelli MS, McDonald D, Miller M, et al. RIP links TLR4 to Akt and is essential for cell survival in response to LPS stimulation. J Exp Med 2004;200: 399-404.

92 McCarthy JV, Ni J, Dixit VM. RIP2 is a novel NFkappaB-activating and cell death-inducing kinase. J Biol Chem 1998;273:16968-16975.

93 Chin AI, Dempsey PW, Bruhn K, et al. Involvement of receptor-interacting protein 2 in innate and adaptive immune responses. Nature 2002;416:190-194.

94 Lu C, Wang A, Dorsch M, et al. Participation of Rip2 in lipopolysaccharide signaling is independent of its kinase activity. J Biol Chem 2005;280:16278-16283.

95 Huang Q, Yang J, Lin Y, et al. Differential regulation of interleukin 1 receptor and Toll-like receptor signaling by MEKK3. Nat Immunol 2004;5:98-103.

96 Hull C, McLean G, Wong F, et al. Lipopolysaccharide signals an endothelial apoptosis pathway through TNF receptor-associated factor 6-mediated activation of c-Jun NH2-terminal kinase. J Immunol 2002;169: 2611-2618.

97 Matsuzawa A, Saegusa K, Noguchi T, et al. ROSdependent activation of the TRAF6-ASK1-p38 pathway is selectively required for TLR4-mediated innate immunity. Nat Immunol 2005;6:587-592.

98 Dumitru CD, Ceci JD, Tsatsanis C, et al. TNF-alpha induction by LPS is regulated posttranscriptionally via a Tpl2/ERK-dependent pathway. Cell 2000;103: 1071-1083.

99 Patriotis C, Makris A, Chernoff J, et al. Tpl-2 acts in concert with Ras and Raf-1 to activate mitogenactivated protein kinase. Proc Natl Acad Sci USA 1994;91:9755-9759.

100 Guha M, O’Connell MA, Pawlinski R, et al. Lipopolysaccharide activation of the MEK-ERK1/2 pathway in human monocytic cells mediates tissue factor and tumor necrosis factor alpha expression by inducing Elk-1 phosphorylation and Egr-1 expression. Blood 2001;98:1429-1439.

101 Matsuguchi T, Masuda A, Sugimoto K, et al. JNKinteracting protein 3 associates with Toll-like receptor 4 and is involved in LPS-mediated JNK activation. EMBO J 2003;22:4455-4464.

102 Arndt PG, Suzuki N, Avdi NJ, et al. Lipopolysaccharide-induced c-Jun NH2-terminal kinase activation in human neutrophils: role of phosphatidylinositol 3kinase and Syk-mediated pathways. J Biol Chem 2004;279:10883-10891.

103 Pollet I, Opina CJ, Zimmerman C, et al. Bacterial lipopolysaccharide directly induces angiogenesis through TRAF6-mediated activation of NF-kappaB and C-Jun N-terminal kinase. Blood 2003;102: 1740-1742.

104 Haimovitz-Friedman A, Cordon-Cardo C, Bayoumy S, et al. Lipopolysaccharide induces disseminated endothelial apoptosis requiring ceramide generation. J Exp Med 1997;186:1831-1841.

105 Kawai T, Adachi O, Ogawa T, et al. Unresponsiveness of MyD88-deficient mice to endotoxin. Immunity 1999;11:115-122.

106 Kawai T, Takeuchi O, Fujita T, et al. Lipopolysaccharide stimulates the MyD88-independent pathway and results in activation of IFN-regulatory factor 3 and the expression of a subset of lipopolysaccharide-inducible genes. J Immunol 2001;167:5887-5894.

107 Hoshino K, Kaisho T, Iwabe T, et al. Differential involvement of IFN-beta in Toll-like receptor-stimulated dendritic cell activation. Int Immunol 2002; 14:1225-1231. 
108 Oshiumi H, Sasai M, Shida K, et al. TIR-containing adapter molecule (TICAM)-2, a bridging adapter recruiting to toll-like receptor 4 TICAM-1 that induces interferon-beta. J Biol Chem 2003;278: 49751-49762.

109 Yamamoto $\mathrm{M}$, Sato $\mathrm{S}$, Hemmi $\mathrm{H}$, et al. TRAM is specifically involved in the Toll-like receptor 4mediated MyD88-independent signaling pathway. Nat Immunol 2003;4:1144-1150.

110 Yamamoto M, Sato S, Hemmi H, et al. Role of adaptor TRIF in the MyD88-independent toll-like receptor signaling pathway. Science 2003;301:640-643.

111 Kaiser WJ, Offermann MK. Apoptosis induced by the toll-like receptor adaptor TRIF is dependent on its receptor interacting protein homotypic interaction motif. J Immunol 2005;174:4942-4952.

112 Fitzgerald KA, McWhirter SM, Faia KL, et al. IKKepsilon and TBK1 are essential components of the IRF3 signaling pathway. Nat Immunol 2003;4: 491-496.

113 Taniguchi T, Ogasawara K, Takaoka A, et al. IRF family of transcription factors as regulators of host defense. Annu Rev Immunol 2001;19:623-655.

114 Sasai M, Oshiumi H, Matsumoto M, et al. Cutting edge: NF-kappaB-activating kinase-associated protein 1 participates in TLR3/Toll-IL-1 homology domaincontaining adapter molecule-1-mediated IFN regulatory factor 3 activation. J Immunol 2005;174:27-30.

115 Lentschat A, Karahashi H, Michelsen KS, et al. Mastoparan, a G protein agonist peptide, differentially modulates TLR4- and TLR2-mediated signaling in human endothelial cells and murine macrophages. J Immunol 2005;174:4252-4261.

116 Grimm J, Sachs M, Britsch S, et al. Novel p62dok family members, dok-4 and dok-5, are substrates of the c-Ret receptor tyrosine kinase and mediate neuronal differentiation. J Cell Biol 2001;154: 345-354.

117 Yamanashi Y, Baltimore D. Identification of the Abland rasGAP-associated $62 \mathrm{kDa}$ protein as a docking protein, Dok. Cell 1997;88:205-211.

118 Di Cristofano A, Carpino N, Dunant N, et al. Molecular cloning and characterization of p56dok-2 defines a new family of RasGAP-binding proteins. J Biol Chem 1998;273:4827-4830.

119 Lemay S, Davidson D, Latour S, et al. Dok-3, a novel adapter molecule involved in the negative regulation of immunoreceptor signaling. Mol Cell Biol 2000; 20:2743-2754.

120 Shinohara $\mathrm{H}$, Inoue $\mathrm{A}$, Toyama-Sorimachi $\mathrm{N}$, et al. Dok-1 and Dok-2 are negative regulators of lipopolysaccharide-induced signaling. J Exp Med 2005;201: 333-339.

121 Bedirian A, Baldwin C, Abe J, et al. Pleckstrin homology and phosphotyrosine-binding domaindependent membrane association and tyrosine phosphorylation of Dok-4, an inhibitory adapter molecule expressed in epithelial cells. J Biol Chem 2004;279: 19335-19349.

122 Itoh S, Lemay S, Osawa M, et al. Mitochondrial Dok-4 recruits Src kinase and regulates NF-\{kappa\}B activation in endothelial cells. J Biol Chem 2005;280: 26383-26396.

123 Pahan K, Raymond JR, Singh I. Inhibition of phosphatidylinositol 3-kinase induces nitric-oxide synthase in lipopolysaccharide- or cytokine-stimulated C6 glial cells. J Biol Chem 1999;274:7528-7536.
124 Martin M, Schifferle RE, Cuesta N, et al. Role of the phosphatidylinositol 3 kinase-Akt pathway in the regulation of IL-10 and IL-12 by Porphyromonas gingivalis lipopolysaccharide. J Immunol 2003;171: 717-725.

125 Schabbauer G, Tencati M, Pedersen B, et al. PI3K-Akt pathway suppresses coagulation and inflammation in endotoxemic mice. Arterioscler Thromb Vasc Biol 2004;24:1963-1969.

126 Fukao T, Tanabe M, Terauchi Y, et al. PI3K-mediated negative feedback regulation of IL-12 production in DCs. Nat Immunol 2002;3:875-881.

127 Guha M, Mackman N. The phosphatidylinositol 3kinase-Akt pathway limits lipopolysaccharide activation of signaling pathways and expression of inflammatory mediators in human monocytic cells. J Biol Chem 2002;277:32124-32132.

128 Pahan K, Liu X, Wood C, et al. Expression of a constitutively active form of phosphatidylinositol 3kinase inhibits the induction of nitric oxide synthase in human astrocytes. FEBS Lett 2000;472:203-207.

129 Strassheim D, Asehnoune K, Park JS, et al. Phosphoinositide 3-kinase and Akt occupy central roles in inflammatory responses of Toll-like receptor 2-stimulated neutrophils. J Immunol 2004;172:5727-5733.

130 Aksoy E, Vanden Berghe W, Detienne S, et al. Inhibition of phosphoinositide 3-kinase enhances TRIF-dependent NF-kappaB activation and IFN-beta synthesis downstream of Toll-like receptor 3 and 4 . Eur J Immunol 2005;35:2200-2209.

131 Opipari Jr AW, Hu HM, Yabkowitz R, et al. The A20 zinc finger protein protects cells from tumor necrosis factor cytotoxicity. J Biol Chem 1992;267: 12424-12427.

132 Wertz IE, O'Rourke KM, Zhou H, et al. De-ubiquitination and ubiquitin ligase domains of A20 downregulate NF-kappaB signalling. Nature 2004;430: 694-699.

133 Evans PC, Ovaa H, Hamon M, et al. Zinc-finger protein A20, a regulator of inflammation and cell survival, has de-ubiquitinating activity. Biochem J 2004;378:727-734

$134 \mathrm{Hu} \mathrm{X}$, Yee E, Harlan JM, et al. Lipopolysaccharide induces the antiapoptotic molecules, A1 and A20, in microvascular endothelial cells. Blood 1998;92: 2759-2765.

135 Lee EG, Boone DL, Chai S, et al. Failure to regulate TNF-induced NF-kappaB and cell death responses in A20-deficient mice. Science 2000;289:2350-2354.

136 O'Reilly SM, Moynagh PN. Regulation of Toll-like receptor 4 signalling by A20 zinc finger protein. Biochem Biophys Res Commun 2003;303:586-593.

137 Boone DL, Turer EE, Lee EG, et al. The ubiquitinmodifying enzyme A20 is required for termination of Toll-like receptor responses. Nat Immunol 2004;5: 1052-1060.

138 Chuang PI, Yee E, Karsan A, et al. A1 is a constitutive and inducible Bcl-2 homologue in mature human neutrophils. Biochem Biophys Res Commun 1998; 249:361-365.

139 Stroka DM, Badrichani AZ, Bach FH, et al. Overexpression of A1, an NF-kappaB-inducible antiapoptotic bcl gene, inhibits endothelial cell activation. Blood 1999;93:3803-3810.

140 Rocha E, Mahiou J, Badrichani AZ, et al. The BH4 domain of A1, an anti-apoptotic bcl family gene, is necessary and sufficient for its antiinflammatory 
function in endothelial cells. Transplant Proc 2001; 33:314.

141 Chinnaiyan AM, O’Rourke K, Tewari M, et al. FADD, a novel death domain-containing protein, interacts with the death domain of Fas and initiates apoptosis. Cell 1995;81:505-512.

142 Choi KB, Wong F, Harlan JM, et al. Lipopolysaccharide mediates endothelial apoptosis by a FADDdependent pathway. J Biol Chem 1998;273:2018520188.

143 Bannerman DD, Tupper JC, Kelly JD, et al. The Fasassociated death domain protein suppresses activation of NF-kappa B by LPS and IL-1 beta. J Clin Invest 2002;109:419-425.

144 Aliprantis AO, Yang RB, Weiss DS, et al. The apoptotic signaling pathway activated by Toll-like receptor-2. EMBO J 2000;19:3325-3336.

145 Burns K, Clatworthy J, Martin L, et al. Tollip, a new component of the IL-1RI pathway, links IRAK to the IL-1 receptor. Nat Cell Biol 2000;2:346-351.

146 Zhang G, Ghosh S. Negative regulation of toll-like receptor-mediated signaling by Tollip. J Biol Chem 2002;277:7059-7065.

147 Bulut Y, Faure E, Thomas L, et al. Cooperation of Tolllike receptor 2 and 6 for cellular activation by soluble tuberculosis factor and Borrelia burgdorferi outer surface protein A lipoprotein: role of Toll-interacting protein and IL-1 receptor signaling molecules in Toll-like receptor 2 signaling. J Immunol 2001;167: 987-994.

148 Lioubin MN, Algate PA, Tsai S, et al. p150Ship, a signal transduction molecule with inositol polyphosphate-5-phosphatase activity. Genes Dev 1996;10: 1084-1095.

149 Sly LM, Rauh MJ, Kalesnikoff J, et al. LPS-induced upregulation of SHIP is essential for endotoxin tolerance. Immunity 2004;21:227-239.

150 An H, Xu H, Zhang M, et al. Src homology 2 domaincontaining inositol-5-phosphatase 1 (SHIP1) negatively regulates TLR4-mediated LPS response primarily through a phosphatase activity- and PI-3Kindependent mechanism. Blood 2005;105:4685-4692.

151 Zippo A, De Robertis A, Bardelli M, et al. Identification of Flk-1 target genes in vasculogenesis: Pim-1 is required for endothelial and mural cell differentiation in vitro. Blood 2004;103:4536-4544.

152 Moritz DR, Rodewald HR, Gheyselinck J, et al. The IL-1 receptor-related T1 antigen is expressed on immature and mature mast cells and on fetal blood mast cell progenitors. J Immunol 1998;161:4866-4874.

$153 \mathrm{Xu}$ D, Chan WL, Leung BP, et al. Selective expression of a stable cell surface molecule on type 2 but not type 1 helper T cells. J Exp Med 1998;187:787-794.

154 Brint EK, Xu D, Liu H, et al. ST2 is an inhibitor of interleukin 1 receptor and Toll-like receptor 4 signaling and maintains endotoxin tolerance. Nat Immunol 2004;5:373-379.

155 Liew FY, Liu H, Xu D. A novel negative regulator for IL-1 receptor and Toll-like receptor 4 . Immunol Lett 2005;96:27-31.

156 Kumar S, Minnich MD, Young PR. ST2/T1 protein functionally binds to two secreted proteins from Balb/c 3T3 and human umbilical vein endothelial cells but does not bind interleukin 1. J Biol Chem 1995;270:27905-27913.

157 Yoshimura A, Nishinakamura H, Matsumura Y, et al. Negative regulation of cytokine signaling and immune responses by SOCS proteins. Arthritis Res Ther 2005;7:100-110.

158 Nakagawa R, Naka T, Tsutsui H, et al. SOCS-1 participates in negative regulation of LPS responses. Immunity 2002;17:677-687.

159 Kinjyo I, Hanada T, Inagaki-Ohara K, et al. SOCS1/ $\mathrm{JAB}$ is a negative regulator of LPS-induced macrophage activation. Immunity 2002;17:583-591.

160 Wang X, Athayde N, Trudinger B. Fetal plasma stimulates endothelial cell production of cytokines and the family of suppressor of cytokine signaling in umbilical placental vascular disease. Am J Obstet Gynecol 2003;188:510-516.

161 Divanovic S, Trompette A, Atabani SF, et al. Negative regulation of Toll-like receptor 4 signaling by the Tolllike receptor homolog RP105. Nat Immunol 2005; 6:571-578.

162 Miyake K, Shimazu R, Kondo J, et al. Mouse MD-1, a molecule that is physically associated with RP105 and positively regulates its expression. J Immunol 1998;161:1348-1353.

163 Hijiya N, Miyake K, Akashi S, et al. Possible involvement of toll-like receptor 4 in endothelial cell activation of larger vessels in response to lipopolysaccharide. Pathobiology 2002;70:18-25.

164 Kishore SP, Bungum MK, Platt JL, et al. Selective suppression of Toll-like receptor 4 activation by chemokine receptor 4. FEBS Lett 2005;579: 699-704.

165 Murdoch C, Monk PN, Finn A. Cxc chemokine receptor expression on human endothelial cells. Cytokine 1999;11:704-712.

166 Wald D, Qin J, Zhao Z, et al. SIGIRR, a negative regulator of Toll-like receptor-interleukin 1 receptor signaling. Nat Immunol 2003;4:920-927.

167 Qin J, Qian Y, Yao J, et al. SIGIRR inhibits interleukin1 receptor- and toll-like receptor 4-mediated signaling through different mechanisms. J Biol Chem 2005;280: 25233-25241.

168 Chuang TH, Ulevitch RJ. Triad3A, an E3 ubiquitinprotein ligase regulating Toll-like receptors. Nat Immunol 2004;5:495-502.

169 Janssens S, Burns K, Tschopp J, et al. Regulation of interleukin-1- and lipopolysaccharide-induced NFkappaB activation by alternative splicing of MyD88. Curr Biol 2002;12:467-471.

170 Janssens S, Burns K, Vercammen E, et al. MyD88S, a splice variant of MyD88, differentially modulates NFkappaB- and AP-1-dependent gene expression. FEBS Lett 2003;548:103-107.

171 Wesche $\mathrm{H}$, Gao X, Li X, et al. IRAK-M is a novel member of the Pelle/interleukin-1 receptor-associated kinase (IRAK) family. J Biol Chem 1999;274:1940319410.

172 Kobayashi K, Hernandez LD, Galan JE, et al. IRAK-M is a negative regulator of Toll-like receptor signaling. Cell 2002;110:191-202.

173 Fritz JH, Girardin SE, Fitting C, et al. Synergistic stimulation of human monocytes and dendritic cells by Toll-like receptor 4 and NOD1- and NOD2activating agonists. Eur J Immunol 2005;35:24592470.

174 Naiki Y, Michelsen KS, Zhang W, et al. Transforming growth factor-beta differentially inhibits MyD88dependent, but not TRAM- and TRIF-dependent, lipopolysaccharide-induced TLR4 signaling. J Biol Chem 2005;280:5491-5495. 